\title{
Between recognition and mis/nonrecognition: Strategies of negotiating and performing identities among white Muslims in the United Kingdom.
}

\author{
Amena Amer \\ London School of Economics and Political Science
}

This article explores white British Muslim experiences of, and strategic performative responses to, the (mis/non)recognition of their seemingly incompatible religious and ethnic identities. Based on in-depth interviews $(\mathrm{N}=26)$, it highlights how the different identity categories they hold relate to one another, influencing processes of perceived recognition in interactional contexts. White British Muslims perceive their ethnic and religious identities to be (mis/not) recognised in complex and contradictory ways. Their identities are affirmed, denied, erased and/or incorrectly ascribed, sometimes simultaneously, by relevant others in different contexts. Performative strategies such as the adoption, maintenance or removal of identity markers are used consciously and agentically in attempts to take back control over how their identities are (mis/not) recognised. At times deliberate performative acts leading to misrecognition are orchestrated by white Muslims themselves to not only minimise the risk of experiencing possible harm or marginalisation but also to transgress and challenge norms. They also assert their multiple identities as a response to (mis/non)recognition and claims of their identities being incompatible, regardless of the repercussions that may result in them being placed at the margins of, or excluded from, their ingroups.

Keywords: identity recognition, social identity, white British Muslims, agency, power, interactional contexts 


\section{Introduction}

Much research in social and political psychology demonstrates that our identities are dynamic and dialogical. Far from being merely static constructs which exist within ourselves, they are negotiated and contested in our interactions with others as we move across contexts. The role of others in processes of identity has long been acknowledged, demonstrating the integral part they play in our self-actualisation and in validating (or invalidating) our belonging to groups (Tajfel \& Turner, 1986, 1979; Turner, Hogg, Oakes, Reicher, \& Wetherell, 1987). Consequently, how we are seen by others, or perhaps more specifically how we think we are seen and what identities we think are recognised or not recognised, influences how we come to understand ourselves in relation to the categories to which we belong. While the concept of recognition has not been explicitly incorporated into psychological theorisation of identity, research has acknowledged the important role that recognition plays in our identity construction, negotiation and performance (Blackwood, Hopkins \& Reicher, 2013; Hopkins \& Blackwood, 2011).

This paper adds to this existing research and explores the concept of recognition and in turn, identity negotiation through performance, in the identity processes and practices of white British Muslims. Being ethnically white British (part of a socially dominant ingroup) and Muslim (part of a socially marginalised and racialised outgroup), they are an informative group through which to explore perceived recognition, particularly in relation to understanding how interactional contexts are consequential for the recognition of seemingly incompatible identities (Amer \& Howarth, 2018; Moosavi, 2015). Furthermore, this paper examines the performative strategies employed to influence and establish a sense of control over how one is seen/identified by others. By drawing out these issues it highlights the 
interplay of recognition and performance in the management of identities in different contexts, further enhancing our theorisation and understanding of social identity processes.

\section{Recognition and social identity}

The extensive work of Henri Tajfel, John Turner and their colleagues (Tajfel \& Turner, 1979; 1986; Turner, Hogg, Oakes, Reicher, \& Wetherell, 1987) on social identity and selfcategorisation (combined to form the Social Identity Approach; Reicher, Spears, \& Haslam, 2010]) argues that we see ourselves and others as individuals as well as members of groups. They stress the dialogical nature of identities, where self-other dynamics are central to validating, and therefore recognising, one's claims to a positive self-concept. Salient attributes which allude to specific social categories become significant to these processes (Reicher et al., 2010). Thus, we see how recognition, defined by Hopkins and Blackwood (2011) as the affirmation of one's identity by others, becomes important for understanding and theorising identity. Moreover, where racialised or stereotyped assumptions are made about one's identity category (misrecognition) or where identities are actively denied and erased by others (referred to in this paper as nonrecognition), we see the very real effects of these processes on the self and feelings of belonging (Blackwood, Hopkins, \& Reicher, 2013).

Concepts related to identity recognition have been explored by a number of researchers in different ways. Some have explored this through the concepts of ascribed and acquired identities (e.g. Pehrson \& Green, 2010; Zlatanović, 2017), others in relation to miscategorisation (Wang, Minervino, \& Cheryan, 2013), and others still talk of voluntary and involuntary identities (Meer, 2008). As Taylor (1994) notes: 
"our identity is partly shaped by recognition or its absence, often by the misrecognition of others, and so a person or group of people can suffer real damage, real distortion, if the people or society around them mirror back to them a confining or demeaning or contemptible picture of themselves. Nonrecognition or misrecognition can inflict harm, can be a form of oppression, imprisoning someone in a false, distorted, and reduced mode of being." (p.25).

Research has demonstrated the negative effects of one's identity not being recognised by others (Barreto, Ellemers, Scholten, \& Smith, 2010; Blackwood et al., 2013). Such examinations of recognition are particularly interesting among individuals who bridge seemingly ‘incompatible’ or conflicting groups e.g. British Muslims (Blackwood, Hopkins, \& Reicher, 2015) or gay religious men (Jaspal \& Cinnirella, 2014). For indeed, experiences of (mis/non)recognition are related to dominant assumptions and understandings by others of which identities 'fit' or do not 'fit' together. While how one's identities are seen and affirmed by others is important, just as crucial are meta-perceptions - how one thinks other people see them (Blackwood et al., 2015). ${ }^{1}$ In a similar vein, Howarth (2002) argues that it is not only how we think others see us that matters, but who these others are, and their ability (or power) to make their representations dominant in society. For indeed, psychological groups that are able to exert influence and control over others, also hold the ability to affect our social worlds which can be hard to resist and change (Hall, 1997; Reicher, 2016; Turner, 2005). However, this does not erase opportunities for contestation and resistance to occur in attempts to challenge which identities become recognised by others. A significant part of this involves

\footnotetext{
${ }^{1}$ Although it is important to note that this is often derived from a general perception of the existing dominant representations of one's group, therefore not necessarily inaccurate.
} 
the performance of identities as a strategy for identity negotiation (Butler, 1990; Hopkins \& Greenwood, 2013; Schlossberg, 2001). Indeed, where one's belonging to a group is perceived to be questioned or doubted, individuals may present themselves strategically to legitimise and emphasise their membership where possible (Cheryan \& Monin, 2005; Wang et al., 2013). The next section will further draw on literature on the performance of identity to expand our understanding of its role in processes of identity recognition and the everyday practice of our identities.

\section{Identity performance: the interconnections of power, agency and interactional contexts}

When our identities are not recognised, denied by others, or perceived as such, we can experience a threat to our sense of self (Barreto, Ellemers, Scholten, \& Smith, 2010; Cheryan \& Monin, 2005; Tajfel \& Turner, 1986). As a result, we draw upon identity presentation and performance strategies (modes of communicative acts such as verbalisations, adopting symbols and signs e.g. in dress) to try to influence identity recognition. Klein, Spears, and Reicher (2007) define performing identity as "the purposeful expression (or suppression) of behaviours relevant to those norms conventionally associated with a salient social identity" (p.30). This emphasis on intention is key to the definition, where any behaviours or performative acts that are not deliberately enacted with the purpose of asserting belonging to a social group are excluded from their conceptualisation of performative strategies. An example of identity performance can be seen in Jaspal and Cinnirella's (2014) study on

British Pakistani Muslim gay men which highlights their participation in fasting during Ramadan as an opportunity to assert, legitimise and safe-guard their Muslim identities within Muslim contexts, where their membership is threatened by their sexual identities. Insights from research on meta-perceptions also becomes relevant here. The evaluative component of 
meta-perceptions - how one thinks one is viewed by others - can instigate particular presentation strategies in a given interactional context (Blackwood et al., 2015; Vorauer, Hunter, Main, \& Roy, 2000). Where mis/nonrecognition is anticipated, performative strategies can be employed to try to assert one's claim to a group in the hope of being recognised. However, such performative strategies are very much an interaction between those attempting to influence their identity recognition and those who can either accept or deny it, emphasising the power dynamics at play. What is more, socially salient identities such as race, gender, and even religion in some cases, may supersede the desired recognition of other identities - and can be particularly problematic where these categories can lead to negative experiences, stigma and stereotyping. In such instances, Khanna and Johnson (2010) argue that strategic 'identity work' such as 'accenting' - the act of highlighting relevant nonstigmatised identities within a particular context - is required to attempt to influence the recognition of these less visible identities. Thus, meta-perceptions provide a guiding frame for modifying, adapting or emphasising certain behaviours and actions, bringing to the fore the interconnections between recognition and identity performance in processes of identity production.

Deliberate acts leading to certain identities not being recognised can also, where possible, be consciously orchestrated and enacted through performance strategies such as verbal identification (or disidentification), or the selective disclosure (or nondisclosure) of various identity categories one holds (Khanna \& Johnson, 2010). In doing so, one may be able to downplay aspects of one's identity in an attempt to be more accepted in another group to which they belong, particularly where these groups are seen as incompatible (Blackwood et al., 2015). Importantly however, these performative acts should not be interpreted as attempts to erase or lie about one's identity multiplicity. As Blocker (1999), states, such acts "are not the function of the kind of artifice or masking that implies a hidden 'real' self" 
(p. 25). They are instead attempts at the "creation and establishment of an alternative set of narratives... creating new stories out of unusable ones" (Schlossberg, 2001, p. 4).

While the power dynamics between those being recognised and those doing the recognising are important to consider, the context in which identities are recognised and how these identities relate to one another within these contexts must also be noted. Our identities do not exist apart from one another, and neither do our experiences of the world play through one identity alone. Therefore we cannot, and should not, study them in isolation reducing identity to single and independent entities (Crenshaw, 1991). The ways in which identities interact and collectively influence our experience must be the lens through which we explore identity processes. Furthermore, in acknowledging the interactional context in which identity recognition and performance plays out we are also able to note how these processes are embedded within social, historical and political structures of power. For indeed, all identity categories are associated with some form of power relations (Brah \& Phoenix, 2004), which inevitably influence how identities are experienced and understood by the self and others.

In the next section, the focus turns to the exploration of identity recognition and performance through the interactional experiences of white Muslims in the UK. We begin by providing some context as to why white Muslims make for a particularly informative group through which to study these issues, before outlining the methodological design of this study.

\section{The current paper: white Muslims in Britain}

What we see above is that while literature on recognition (including perceived recognition) and performance in relation to identity processes exists, psychological theories of identity do not explicitly draw all of these strands together and acknowledge the critical role they play in 
identity processes. The current paper attempts to go some way in demonstrating how these issues (recognition, perceived recognition and performance) interlink and are at the forefront of identity negotiation. It does so through a study on white Muslim identities in the British context.

According to the latest figures from the 2011 Census of England and Wales, ethnically white Muslims make up $8 \%$ of Muslims², $36 \%$ of whom identified specifically as 'white British' (Office for National Statistics, 2011). Many of these are converts to the religion, although some are also inevitably 'born into' the religion, being descendants of white British people who had converted to Islam (Amer \& Howarth, 2018). ${ }^{3}$ White Muslims have been described as a "minority within a minority" (Brice, 2011); a group with a unique set of experiences and challenges, despite sharing some of these experiences with other Muslims. They do so within a context which heavily racialises Muslims as 'brown' and the racialised 'other', and marginalises them due to the alleged threats they pose, both in relation to British (and Western) culture and national (and international) security (Jaspal \& Cinnirella, 2010; Meer, 2013; Moosavi, 2002, 2015; Phillips, 2006). Furthermore, the intersections of religion and gender, where markers of Islam are often much more salient for women through the wearing of the hijab (headscarf), adds another dimension to experiences of recognition within this context (Amer \& Howarth, 2016; Hopkins \& Greenwood, 2013).

While a significant amount of literature exists on British Muslim identities in the UK context, little has been conducted on ethnically white Muslims. Being both white and Muslim, their identities are often perceived as incompatible or an unlikely combination (Amer \& Howarth, 2018; Meer, 2013; Moosavi, 2015). Thus, the nuances of straddling both

\footnotetext{
${ }^{2}$ Muslims make up 4.8\% of population in England and Wales (Office of National Statistics, 2011).

${ }^{3}$ We are able to make this assertion due to the fact that most individuals who many also be consider 'white Muslims' such are those who are descendants of people from the Balkans for example, where there is a history of Islam and Muslim communities, often identify as 'other white' (Vaos, 2013) thus it is unlikely that a large proportion would be a part of the 'white British' category here.
} 
a dominant ingroup and a minority outgroup (as well as acknowledging the interconnections with gender) provide an interesting frame through which to examine multiple and complex identities in experiences of recognition and belonging. In addition, exploring the performative strategies undertaken by such a group in relation to recognition can highlight the significance of power and agency to this process.

The current study explores the following research question: How do white Muslims perceive their identities to be recognised in different interactional contexts and how do they manage their various identity performance strategies as a result?

\section{Method}

\section{Participants}

Twenty-six self-identifying white British Muslims participated in the study (11 female, 15 male, ages 24-78 $(M=45))$. All bar one participant had converted to Islam. The one nonconvert was brought up Muslim, her parents having converted to Islam prior to her birth. Those who had converted did so at various stages in their lives (e.g. as teenagers, at university, later in life) and had been Muslim for at least four years at the time of the interview.

Participants were recruited via a call-out on social media and through snowballing. All participants were given pseudonyms. Those with English names were given English pseudonyms and those with Arabic/Islamic names were given Arabic/Islamic pseudonyms.

\section{Data collection}

The data was collected using semi-structured interviews and explored themes relating to selfidentification, the practice and visibility of identity and perceived identification by others. 
Interviews were conducted across England (Birmingham, Colchester, Dover, Gloucester, Leeds, London, Luton, Manchester, Milton Keynes, Wolverhampton) and Wales (Cardiff). They lasted between 70-180 minutes ( $M=118$ minutes), were audio-recorded and transcribed verbatim.

\section{Analytical method}

The interviews were analysed using Thematic Analysis (Braun \& Clarke, 2006). A codebook was generated after the analysis of ten interviews which was then applied to the remaining interviews. As these interviews were coded, relevant modifications were made to the codebook which, upon completion of the analysis, consisted of twenty-three codes, eight themes and two overarching global themes. Four interviews were double-coded by another researcher and any discrepancies were discussed with adjustments made to the coding framework.

A Thematic Analysis was selected for its ability to allow researchers to organise and identify patterns and inconsistencies in the data that aid in answering the research questions. Braun and Clarke (2006) note that it is important to acknowledge the active role of the researcher in identifying and sorting out the patterns, commonalities and inconsistencies across the interview transcripts. Themes do not simply residing in the data but are consciously selected and emphasised by the researcher because they "capture something important about the data in relation to the research question, and represents some level of patterned response or meaning within the data set” (Braun \& Clarke, 2006, p. 10). Furthermore, research is not conducted in a vacuum, thus it is important that the researcher acknowledges coding as decisions rooted in theoretical and epistemological perspectives. In the next section, I discuss this in relation to my own identity. 


\section{Reflexivity: situating the researcher}

It is crucial that researchers are open and aware of their identities and positionalities when conducting research and how this can influence both the data collection and its interpretation (Howarth, 2002). Having conducted the interviews myself, participants were often curious about my own identity and my personal connections to the research. Wearing the hijab makes my Muslimness obvious, yet my mixed ethnic heritage (white-European and Arab) is less evident and am often positioned as fully Arab/Middle Eastern. Finding out my mother is a white Muslim put many participants at ease believing that I would understand and appreciate the complexities of their experiences. Bhopal (2010) notes that personal experiences and 'presentation of self' are important components of the researcher-participant dynamic. Indeed, sameness between researcher and participant does not by any means weaken the strength of the analysis (Phoenix, 1994). Rather, it can enable importance to be attributed to parts of the data which may otherwise be overlooked.

While I can understand participant experiences to some extent, my identity as a researcher needs to be acknowledged, and as Phoenix (1994) highlights, the differences and power imbalances between the researcher-participant relationship remained.

\section{Results and discussion}

All participants discussed experiencing identity recognition (affirmation by others), misrecognition (racialised and stereotyped assumptions being made) and nonrecognition (active denial and erasure). The contexts in which these processes took place, which identities were pertinent within the contexts and who the relevant others were, played a crucial role in these experiences, highlighting the interconnections and perceived tensions between religious identity, ethnic identity and space. 
Many participants expressed feelings of being placed at the periphery (consciously or otherwise), or excluded entirely, from particular identity groups they considered themselves a part of. Participants shared how they strategically performed their identities in different, context-specific ways. These intentional behaviours served as attempts to regain a sense of control over how they perceive themselves to be recognised by others. Interestingly, the two contexts in which identity recognition became relevant for participants were either made up of predominantly white non-Muslims or heritage (non-white) Muslims. Contexts that were more mixed (i.e. both Muslim and white non-Muslim) were not discussed, suggesting the significance of identity norms, assumptions and expectations that can exist within more identity homogenous spaces on experiences of recognition.

Below, two global themes are discussed; 1) The cost and value of identity recognition, exploring the experience of perceived (mis/non)recognition and the interaction of identities in context and 2) Identity presentation: transgression, assertion and avoiding group exclusion, highlighting the identity performative strategies employed to influence their experiences of recognition.

\section{The cost and value of identity recognition}

The cost of recognition as Muslim: nonrecognition of whiteness, misrecognition as not white and the effects on cultural identity

In perceiving to have their Muslim identities recognised, interviewees discussed how this had consequences for recognition of their ethnic and cultural identities. At times, this was described in relation to reactions of members of their white majority ingroup, particularly family and friends in response to their conversion. Participants feel their conversion is 
understood as not only a change of religion and/or ideology, but also a change in ethnic and cultural identity and belonging;

\author{
Extract 1: Jessica \\ “When I converted people kind of couldn't believe it, I faced a lot of \\ backlash, some family members and friends really struggled with it, they sort \\ of felt I was no longer one of them, as though I'd given up my culture and \\ were expecting me to start acting Asian, even with food and things like that".
}

In her experience, Jessica's ethnic identity as white British had been erased by others as a result of her conversion and was replaced with the projection of an 'Asian' cultural identity. This active nonrecognition of her whiteness reflects the prism through which Islam and Muslims are often viewed by many white majority groups - that is as foreign, other, and incompatible with what it means to be white and British (Amer \& Howarth, 2018; Moosavi, 2015). Moreover, within the context of 'othering' Islam as non-British, the act of becoming Muslim brings to the fore socially and politically embedded notions of whiteness and nationalism as being rooted in Christianity (Amer \& Howarth, 2016; Phillips, 2006). It becomes an 'either/or' scenario, where being recognised as white British is contingent upon one not being Muslim. Thus, being white British and Muslim, becomes an impossibility, resulting in white Muslims' cultural and ethnic identity being consciously stripped away in this act of nonrecognition. This is highlighted further in a quote from Mustafa, who recalls his friend's reaction to his conversion: "He couldn't understand, he literally said: You ain't white no more, how can you be?". Indeed, literature on the racialisation of Islam demonstrates how Islam is seen as a religion that is for, and made up of, 'brown bodies' (predominantly people of South Asian or Arab heritage) and the extent to which this has 
consequences on those concerned in relation to their experiences of belonging (Meer, 2013;

Wykes, 2013). This is seen again in extract 2:

\begin{abstract}
Extract 2: Katherine
"I was lost in Cheltenham and I couldn't figure out where I was going, and I clearly looked lost because this woman, probably in her 40s, she stopped and asked me really slowly whether I was OK and put her thumbs up. I told her the place I was looking for. She looked surprised and told me that I spoke really good English. I was like "I am English" and she was like "Oh, I thought you were foreign because of the scarf on your head'. She wasn't rude, but she just assumed I wasn't English because of the hijab. ”
\end{abstract}

This quote from Katherine sheds light on how visible markers of one's religious identity play a significant role in the misrecognition of racial and ethnic identity by nonMuslims, as a result of dominant racialised representations of Islam and Muslims (Moosavi, 2015; Özyürek, 2015). Echoing the findings of Garner and Selod (2015) on the consequences of racialisation, the presence of the hijab drew attention to Katherine's Muslim identity rendering her "foreign" both ethnically, by eliminating any possibility of her Englishness (and her whiteness), and culturally through surprise in her ability to speak English.

Similar scenarios were recounted by a number of female participants who choose to wear the hijab, demonstrating how, in the case of adopting a religious marker (e.g. wearing the hijab, the $n i q a b^{4}$ or the $\left.a b a y a h^{5}\right)$, gender intersects prominently with the experiences of religious, cultural and ethnic identity recognition or mis/nonrecognition among white

\footnotetext{
${ }^{4}$ Face veil worn by some Muslim women.

${ }^{5}$ Long, dress-like attire worn by some Muslim women. Often worn by women in the Middle East, specifically countries in The Gulf, but has increased in popularity among Muslims in other countries across the globe.
} 
Muslims women (Brah \& Phoenix 2004). Interestingly, while the presence of markers of Muslimness among some women identify them as Muslim and strips them of their ethnic and cultural identities, markers adopted by male participants (e.g. having a beard) are more subtle and ambiguous, often resulting in their whiteness still being recognised and their Muslim identity being overlooked (Amer \& Howarth, 2016; Hopkins \& Greenwood, 2013). As Reicher et al. (2010) note, present or absent salient markers of group membership can play a significant role in one's inclusion in or exclusion from a given group - the process of which is very much dependent on recognition.

The examples above focused on the interactional processes of identity recognition within non-Muslim contexts. Within these contexts, perceived recognition as Muslim resulted in the non/misrecognition of their ethnic and cultural identities and the projection of one that is Asian or 'foreign'. Within Muslim contexts however, while their whiteness was not denied as such, their recognition as Muslim was heavily embedded in the imposition of a new cultural identity. Many participants, particularly those who had converted to Islam, talked of the expectation for them to shed markers of their whiteness and to replace these with religious and cultural markers such as, discarding their English names and instead adopting Arabic ones and taking on a local Muslim community's cultural styles of dress. In doing so, they are required to dilute their association to their whiteness and in turn validate their Muslim identities through such acts and behaviours (see extract 3).

\section{Extract 3: Becky}

"As soon as I became Muslim, almost the next day, people [other Muslims] expected me to start wearing the hijab, dressing a certain wayeven for Eid, to wear cultural clothes. Those aren't my clothes! I was even 
expected to change my name. [...] It was like I've now started a new life, so everything else is in my past."

Parallels may be drawn with what was discussed earlier in relation to white nonMuslim majority group members associating conversion to Islam with having changed cultures. Here however rather than being stripped of her whiteness by others, Becky describes how she was also expected to actively erase her whiteness herself after having converted. Interestingly, women were often under more pressure than men to conform to these demands and expectations by Muslim communities highlighting the different experiences in relation to identity recognition and its consequences between white Muslim females and males. As Suleiman (2013), notes, not doing so, could call into question the authenticity and extent of their Muslimness demonstrating the conditionality for the extent to which one's Muslimness is recognised resulting in them potentially being cast out or on the periphery of not only their white ingroup for being Muslim, but also their Muslim ingroup for not conforming to normative group behaviour.

The value and cost of recognition as white: Muslim identity being celebrated and doubted

While above participants talked of their whiteness being mis/not recognised because of their Muslimness, they also discussed the perceived recognition of their white identities and the consequences on their Muslim identities. Many participants described how there was an overemphasis on, or to use Renault's (2009) term, over-visibility of, their identity as (white) converts in Muslim contexts. This often led to questions being posed about their Muslimness, casting doubt on their loyalty and dedication to Islam (extract 4: Aidan). 


\author{
Extract 4: Aidan \\ "I remember once I went to meet a sister and her family, looking into \\ marriage and stuff. It was a [sic] old Bengali uncle. He goes to me, \\ "You've been Muslim for five years now, you planning on staying \\ Muslims?" I was like, what? How do you-?! I was planning on doing an 8- \\ year stint, as a Muslim before giving Buddhism a try. Much more trendy \\ these days!"
}

Aidan's quote demonstrates how white Muslims are perceived to be ascribed a 'lower grade' of Muslimness by other Muslims and are positioned as 'second-class' Muslims because many have converted into the religion unlike those 'born into' the religion. Although his Muslim and white identities were both perceived to be recognised, how far Aidan's Muslimness is recognised and seen as 'authentic' (Suleiman, 2013; Taylor, 1994) is rooted in questioning his commitment because of his conversion and his whiteness. This suggests that identity recognition processes are somewhat similar to a scale, whereby the degree of recognition is dependent on the interconnections of other identities. Parallels can be drawn with work on identity prototypicality (e.g. Cheryan \& Monin, 2005; Turner et al., 1987) and what this means for feelings of recognition, acceptance and belonging when one is seen as a peripheral, rather than a prototypical member of a group. In this way, there is an allusion to power asymmetries and what it means to belong, as an equal, to a group.

However, there were also instances when participants expressed feeling their identities, as both white and Muslim, were equally recognised by other Muslims. Here their whiteness was perceived to be maintained and recognised because of their religious identity (see extract 5). 


\begin{abstract}
Extract 5: Donna
"White Muslims get put on a pedestal. I was in a mosque and this woman saw me, and people always assume like, "oh are you a convert" because they see the pale skin [...] and she was like "Oh Mashallah [praise be to God] Mashallah, amazing!" and I pointed to my friend [also a convert], she's Chinese and she was like "oh" and kind of ignored her."
\end{abstract}

This narrative of white Muslims being highly valued and even celebrated for their conversion, and their whiteness bringing validity and recognition to their Muslimess was not uncommon among the interviewees. In fact, many noted how other converts from Black and ethnic minority backgrounds are not given "conversion points" (Timothy, 41, Luton) in the same way that white Muslim converts are, with their conversion often being ignored and not acknowledged. Indeed, Suleiman (2013) notes that many white Muslims feel they are treated as 'trophies' and that '[b]ecause White- and Western- are perceived to be best, when a White Westerner chooses Islam it appears to validate Islam as a religion” (p.75). These sentiments were echoed throughout the interviews. Thus we see how ethnic and religious identity intersect in the experiences of recognition (Brah \& Phoenix, 2004; Crenshaw, 1991). Furthermore, we see how power dynamics play an important role in recognition processes. In these example above, a socially and politically more powerful identity category (ethnicity) appears to elevate the status of one that is marginalised (religion) for those who are in the religious ingroup in question (see also Petsko \& Bodenhausen, 2019, for similar findings in relation to sexual and racial identity). 
The first global theme illustrates how experiences of (mis/non)recognition are shaped by the interactional context, which in turn have consequences for white Muslims being recognised as both white and Muslim. The complexities and contradictions in identity recognition across contexts demonstrate the intricate interconnections between who is doing the recognising, and what the recognition of particular identities means in relation to systems of power and position. A central part of these experiences is the presence or absence of identity markers (Reicher et al., 2010) thus this theme opens the stage for further critical examination of the role of recognition in identity processes and experiences. In the next section we look at how participants strategically perform and negotiate experiences of identity recognition (including its denial) in different contexts.

\section{Identity presentation: transgression, identity assertion and avoiding group exclusion}

All participants were strategic in how they performed their identities. They discussed how their previous experiences of (mis/non)recognition influenced their choices and reasons for various strategies. Moreover, they noted how context and who the relevant other was influenced their performative strategies with many adapting and altering their strategies across these contexts.

In non-Muslim spaces, many participants expressed strategically downplaying or concealing their Muslim identities and instead highlighting their contextually non-stigmatised identity i.e. being white (see Khanna \& Johnson, 2010; Klein et al., 2007). Doing so facilitated their acceptance into spaces where being identified as Muslim may have caused discomfort, harm or exclusion through being rendered an outcast. In extract 6, Matthew shares his thoughts and experiences; 


\begin{abstract}
Extract 6: Matthew
"I mean on this estate [where he lives] I normally just introduce myself as Matthew, and one of the reasons is we've only been here for four years and I'm-well, I know a lot of people in the area now but I've noticed a lot of them tend to be quite negative towards Muslims so it both allows me to hear what they are saying, keep my ear to the ground. The other thing is if they know me as Matthew and then later on they discover I am Muslim, after getting to know me, maybe that will help give them a better impression, whereas if they already know I'm Muslim they'll probably jump to conclusions already and no-one will bother getting to know me."
\end{abstract}

What Matthew described draws on Hollander's (1958) work on idiosyncrasy credit where establishment of credibility, likability and acceptance are crucial steps before dissent or deviation from prototypical behaviours can effectively take place. Interestingly, while processes of recognition are often talked of as being done by others (e.g. Taylor, 1994), here we see an example of how it can be actively and agentically orchestrated by white Muslims themselves. Meta-perceptions become crucial here in that they aid in the anticipation of possible negative attributions as a result of recognition of their Muslimness, thus allowing participants to regain a sense of control over the situation (Vorauer et al., 2000). This temporary concealment of their Muslimness is seen as a momentary compromise that potentially has broader, more positive, effects on perceptions of Muslims by non-Muslims "help[ing] give them a better impression".

The absence of visible markers of Muslimness, and thus not being recognised as such, holds power in the example above (see Hopkins \& Blackwood, 2011). Gender plays a crucial role here, in that male participants were often critically aware of their ability to be recognised 
as white and not Muslim due to the absence of religious markers. What is more interesting however, is that male participants also noted being able to be recognised as white (and misrecognised as not Muslim as a result) even with the presence of a chosen Muslim marker - the beard (see extract 7). Many in turn acknowledge how this put them in a position of privilege to be more easily accepted into mainstream non-Muslim spaces compared to other Muslims.

\section{Extract 7: James}

"because I'm white, and only have a beard that can be interpreted as me being a hipster, my Islam is less salient in the eyes of the outsiders, so I can navigate mainstream society with my faith being unknown. Less so for Muslims who happen to be from a minority ethnic background, or Muslims who happen to be female and observe a certain style of dress."

Interestingly, the beard was the performative religious identity marker of choice among most of the male participants interviewed and many noted (as can be seen with James' quote above) that it does not, by any means, have a definitive association with Islam. Its ambiguity gives white Muslim men flexibility as it has different context-specific meanings and identities ascribed to it. On the one hand, its salience allows them to avoid feeling excluded from their white ingroup because where their whiteness is perceived to be recognised, the beard, in this interactional context, ascribes them with the label "hipster" rather than being recognised as Muslim. On the other hand however, in predominantly Muslim contexts or in interactions with Muslims, the meaning of the beard is perceived to be understood as a more explicit marker of religious identity thus allowing their Muslim identity to be recognised and acknowledged - "[Muslims] are less suspicious when I walk into a 
mosque because it makes a bit more sense. I've got the look” (Mustafa). In this way, anticipating how others perceive the beard, and its consequences on their religious identity recognition and acceptance into different spaces enables white Muslim men to traverse different contexts with ease while simultaneously maintaining a performative element of their religious identity. In fact, where male participants expressed choosing to take on other markers of their Muslimness - ones that were much more explicitly Muslim, for example, wearing a jilbab (Middle Eastern robe) or a taqiyah/kufi (type of cap/hat) - they did so only when attending the mosque or Muslim-majority gathering where such visual displays and markers of religious identity are seen as the norm and would, as in the case of the beard, validate their presence further.

White Muslim women did not share examples of performative religious markers that had ambiguous meanings. However, they did discuss the way in which performative markers and context interacted and shaped possible consequences for belonging (extract 8):

\author{
Extract 8: Fatima \\ "I was going on a coach trip to Cornwall. It was all old white couples or \\ individuals or groups of friends. I wasn't going to wear my hijab. I would \\ stand out. But of course, when I go into Muslim spaces I do wear the hijab, \\ I'm more easily identified as Muslim and there are no questions regarding \\ my faith."
}

Here, we see how the meaning (and use) of the hijab is context specific and there is an awareness of how it can function as a marker of difference and exclusion as well as a marker of sameness and inclusion. Therefore, it is used strategically to ensure the recognition (or 
misrecognition) of their religious identity in a way that is relevant to specific spaces, with a clear understanding of what would be at stake if this is not done. Wagner, Sen, Permanadeli, and Howarth (2012) find similar strategies in their study on practices of veiling in Indonesia and India. The adoption of the hijab is contextually driven; being worn or removed to ensure one does not stand out in a given space and so becoming a target of unwelcome representations of difference. It highlights the conscious and reflective thought that goes into expressions, or suppressions, of identity through the adoption, or avoidance, of specific markers in order to be accepted in certain spaces (Blackwood et al., 2015; Schlossberg, 2001). How one thinks one will be seen by others, which identities will be affirmed or not affirmed and what this means in relation to borders of belonging and exclusion are all issues that are considered (Blackwood et al., 2015; Hopkins \& Blackwood, 2011). This strategic negotiation of identity through the use of markers highlights how individuals agentically seek to temporarily shift the power dynamics of processes of recognition, applying some control over how they wish to be positioned and recognised by relevant others. In doing so, they attempt to achieve a positive self-concept through doing what is seen as necessary to be recognised as a part of contextually relevant groups (Reicher et al., 2010; Tajfel \& Turner, 1986, 1979; Turner et al., 1987).

In other examples of strategic identity performance, predominantly found in relation to experiences in Muslim contexts, white Muslims sometimes used their recognition as white converts to Islam, and thus non-prototypical members of the ingroup, to challenge the norms in some Muslim communities (extract 9: Aidan).

Extract 9: Aidan 
"It's kind of empowering to be outside of the very many norms [...] being a white Muslim, being a white convert, like, that's rare enough, you're kinda given carte blanche [...] It's not unheard of to play a bit dumb especially if it's doing something that I don't think is a bit forward thinking [...] for example we [him and his wife] went to the masjid [mosque], and I knew it was kind of a hard-core mosque - no women in the mosque kind of thing. It was prayer time. I needed to pray. My wife needed to pray. I was like "Come, we're going in". And when they were all kicking off on me, I was like "It's a mosque". I played dumb."

In his awareness of being recognised as white and as a convert, Aidan describes how he strategically played into assumptions held by some Muslims of converts as lacking in knowledge of cultural norms and practices of Islam. He confidently uses his knowledge of Islam as not excluding women from religious spaces and the need for his wife to pray to override exclusionary cultural interpretation of the religion. He noted the relatedness of being a convert with being white and demonstrated the power this affords him to resist and challenge (Özyürek, 2015). This highlights how power is a critical part of identity negotiation, performance and recognition, particularly in relation to how we strategically position ourselves and perform our identities in response to how we perceive others' to recognise us (Blackwood et al., 2015; Klein et al., 2007).

Interestingly, while a few women did share examples of acts of resistance led by themselves (see extract 11 below for an example), such explicit acts of transgression were generally a rarity among the female participants interviewed, suggesting that there are also gender power dynamics at play. Indeed, even in the extract above, Aidan's wife who was complicit in the act of resistance (although she is not white and thus is not the focus of the 
research) did not actively engage with the men at the mosque according to the narrative. Rather, it was her husband who was at the forefront of the exchange on her behalf.

Many women expressed being wary of how their explicit resistance and challenging of some traditions and practices may negatively impact them, destabilising their feeling of belonging in Muslim contexts where their position can, at times, already be precarious (as demonstrated previously in extract 8). This draws attention to how white Muslim females actively consider the interactions of their gender, religious and ethnic identities in context and how these sit within power asymmetries (Brah \& Phoenix, 2004). As a result, the majority of female participants were also cautious of asserting their identities as white and Muslim in contexts where one was felt to be either erased or not recognised. Interestingly however, some did share examples of identity assertion, demanding recognition for the multiple and interconnecting identities and breaking down perceptions of identity incompatibility and contradiction (extract 10):

\author{
Extract 10: Jane \\ "I don't need to change my name. It was given to me by my parents, so I \\ won't change it. Wearing the hijab is also important to me, it shows a part \\ of me and I'm proud of all the things that show a different part of me, even \\ if it confuses other people or goes against what they think".
}

While Jane's declaration is powerful, this assertion does not guarantee recognition by others, raising questions about what this means for identities that are important parts of one's self-concept and their recognition being integral to feelings of belonging (Cheryan \& Monin, 2005). Nevertheless, it demonstrates how agency is used to challenge the mis/nonrecognition of a nuanced and multifaceted identity. Jane is not afraid of the cost of such determination, or 
the potential exclusion from these ingroups. She remains steadfast in being true to herself, be that when among other Muslims by keeping her English name, or among non-Muslims by wearing the hijab. Yet, performative acts of assertion of Muslim identities in non-Muslim context were not so frequently discussed in the interviews, particularly in comparison to asserting their identities as white in Muslim contexts where for example, white Muslims were expected to shed parts of their cultural heritage as English or white (extract 11):

\author{
Extract 11: Andrew \\ "Some [Muslims] struggle with accepting calling me Andrew, they want \\ me to use an Arabic name, but I insist on it. There is nothing unIslamic \\ or disrespectful about it, so Islam does not require me to change it."
}

Andrew's willingness to potentially be placed at the margins of his Muslim ingroup by not fully adhering to the cultural norms and expectations of its gatekeepers, and resisting expectations to erase his whiteness, speaks to the context-specific power dynamics at play. He uses his knowledge and understanding of Islam in a similar way to what was previously seen in extract 9. James' assertion and demand for recognition of his identity as white in the face of its active denial results in a conscious and vocal declaration and performance of his ethnic identity (Khanna \& Johnson, 2010; Klein et al., 2007). In doing so, he embodies the compatibility of his religious and ethnic identities that are seen as at odds with one another. This becomes an important step in achieving a positive sense of self (Reicher et al., 2010; Tajfel \& Turner, 1986) and places white Muslims at the forefront of challenging not only how they are positioned in relation to boundaries and norms of group belonging, but also, how identities that are seen as incompatible come to be understood. 
In this section the various ways that white Muslims perform their identities for, and in response to, perceived (mis/non)recognition have been explored. White Muslims call on a range of strategies, with the choice of strategy depending on the context they are in, the relevant others within these contexts and what identities they believe to be at stake. At times white Muslims choose performative strategies that may result in aspects of their identities not being recognised for fear of harm or exclusion, while at other times they intentionally assert their multifaceted identities in acts of resistance, despite the potential consequences of doing so. Importantly, this section highlights how identity recognition and performance are intrinsically embedded in processes of identity and that the interactional contexts in which these processes take place are consequential for identity (mis/non)recognition and the various strategies employed to orientate and navigate these experiences.

\section{Conclusion}

Our identities are in a constant state of being shaped, contested and challenged in relation to real or imagined others (Reicher, 2004; Reicher et al., 2010; Tajfel \& Turner, 1986; Turner et al., 1987). Thus, identity recognition, or indeed perceived identity recognition, becomes integral to our understanding of identity. The present study has brought to the fore some of the way that identities are not recognised, through being actively denied, erased or incorrectly ascribed. It explored experiences of, and responses to, perceived identity (mis/non)recognition and how performative strategies are used among individuals with multiple and seemingly incompatible identities. With a focus on the experiences and testimonies of white Muslims in the UK, the paper has highlighted how recognition and identity performance are interlinked. Salient markers of identity influence identity 
(mis/non)recognition, which in turn inform performative strategies undertaken in attempts to pre-emptively establish a sense of control over what identities come to be recognised or not recognised as well as the costs and benefits that accompany these processes. As such, the identity performance of white Muslims is reflexive and becomes shaped by the context, the identities that are pertinent to it, the relevant others within it, and the power dynamics that permeate it (Hopkins \& Greenwood, 2013). Indeed, what becomes important to note is the intentional and agentic strategies of performance that lead to deliberate moments of misrecognition. These are orchestrated in order to avoid possible harm, discomfort, marginalisation or even exclusion from a contextually relevant group. Furthermore, the multiple components of their identities are also at times intentionally asserted and performed, actively challenging representations of ethnic and religious incompatibility or the confinement of identities into one-dimensional constructs. While recognition by others of their identities as multifaceted and complex is not necessarily achieved, this act remains important. It becomes an act of resistance to the power others have in defining and controlling one's sense of self and identity (Coulthard, 2014).

This paper provides a detailed example of the complexities of multiple, seemingly incompatible identities, and how they sit in relation to dynamics of power. It highlights some of the nuanced understandings of identity that can emerge from placing recognition and performative strategies at the centre of social identity research. With a focus on identities that are often seen as incompatible, this paper demonstrates how these are performed, managed, used strategically and asserted in relation to perceived recognition. Furthermore, who is understood to be doing the (mis/non)recognition, where this is being done and what identities are at stake, are all critical questions that must be incorporated into identity research, particularly in relation to strategies of identity negotiation. For not only is the role of 
recognition in identity processes central, it is in fact the main thread through which identity construction, negotiation, performance and resistance are connected.

\section{References}

Amer, A., \& Howarth, C. (2016). Représentations sociales et identité : vers un rapprochement entre ethnie, religion et pouvoir. In G. Lo Monaco, S. Delouvée, \& P. Rateau (Eds.), Les représentations sociales. Théories, méthodes et applications (pp. 437-542). Louvain-laNeuve, Belgium: De Boeck Superieur.

Amer, A., \& Howarth, C. (2018). Constructing and contesting threat: Representations of white British Muslims across British national and Muslim newspapers. European Journal of Social Psychology, 48(5), 614-628. doi:10.1002/ejsp.2352

Barreto, M., Ellemers, N., Scholten, W., \& Smith, H. (2010). To be or not to be: The impact of implicit versus explicit inappropriate social categorizations on the self. British Journal of Social Psychology, 49(1), 43-67. doi:10.1348/014466608X400830

Bhopal, K. (2010). Researching South Asian women: issues of sameness and difference in the research process. Journal of Gender Studies, 10(3), 276-286. doi:10.1080/0958923012008648

Blackwood, L., Hopkins, N., \& Reicher, S. (2013). I know who I am, but who do they think I am? Muslim perspectives on encounters with airport authorities. Ethnic and Racial Studies, 36(6), 1090-1108. doi:10.1080/01419870.2011.645845

Blackwood, L., Hopkins, N., \& Reicher, S. D. (2015). 'Flying while Muslim': citizenship and misrecognition in the airport. Journal of Social and Political Psychology, 3(2). doi:10.5964/jspp.v3i2.375

Blocker, J. (1999). Where is Ana Mendieta? Durham, NC: Duke University Press. Brah, A., \& Phoenix, A. (2004). Ain't I A Woman? Revisiting Intersectionality. Journal of 
International Women's Studies, 5(3), 75-86.

Braun, V., \& Clarke, V. (2006). Using thematic analysis in Psychology. Qualitative Research in Psychology, 3(2), 77-101.

Brice, M. A. K. (2011). A minority within a minority: A report on converts to Islam in the United Kingdom. Retrieved from https ://faith-matte rs.org/image s/stori es/fm-repor ts/a-minor ity-within-a-minor ity-a-report-on-conve rts-to-islam-inthe-uk.pdf

Butler, J. (1990). Gender Trouble. New York: Routledge.

Cheryan, S., \& Monin, B. (2005). "Where are you really from?”: Asian Americans and identity denial. Journal of Personality and Social Psychology, 89(5), 717-730. doi:10.1037/0022-3514.89.5.717

Coulthard, G. S. (2014). Red Skin White Masks. Minneapolis, MN: University of Minnesota Press.

Crenshaw, K. (1989). Demarginalizing the intersection of race and sex: a Black Feminist critique of antidiscrimination doctrine, Feminist Theory and antiracist politics. University of Chicago Legal Forum, 1(8). doi:10.1016/0011-9164(90)80039-E

Crenshaw, K. (1991). Mapping the Margins: Intersectionality, Identity Politics, and Violence against Women of Color. Stanford Law Review, 43(6), 1241-1299. doi: $10.2307 / 1229039$

Garner, S., \& Selod, S. (2015). The Racialization of Muslims: Empirical Studies of Islamophobia. Critical Sociology, 41(1), 9-19. doi:10.1177/0896920514531606

Hall, S. (1997). Representation: Cultural Representations and Signifying Practices. London: Sage.

Hollander, E. P. (1958). Conformity, status, and idiosyncrasy credit. Psychological Review, 65(2), 117-127. doi:10.1037/h0042501

Hopkins, N., \& Blackwood, L. (2011). Everyday citizenship: Identity and recognition. 
Journal of Community \& Applied Social Psychology, 21, 215-227. doi:10.1002/casp

Hopkins, N., \& Greenwood, R. (2013). Hijab, visibility and the performance of identity. Journal of Social Psychology, 43, 438-447.

Howarth, C. (2002). Using the theory of social representations to explore difference in the research relationship. Qualitative Research, 2(1), 21-33.

doi:10.1177/1468794102002001637

Jaspal, R., \& Cinnirella, M. (2010). Media representations of British Muslims and hybridised threats to identity. Contemporary Islam, 4, 289-310. doi:10.1007/s11562-010-0126-7

Jaspal, R., \& Cinnirella, M. (2014). Hyper-affiliation to the religious ingroup among British Pakistani Muslim Gay men. Journal of Community and Applied Social Psychology, 24(4), 265-277. doi:doi:10.1002/casp.2163

Khanna, N., \& Johnson, C. (2010). Passing as black: Racial identity work among biracial americans. Social Psychology Quarterly, 73(4), 380-397.

doi:10.1177/0190272510389014

Klein, O., Spears, R., \& Reicher, S. (2007). "Social Identity Performance”: Extending the strategic side of SIDE. Personality and Social Psychology Review, 11(1), 28-45.

Meer, N. (2008). The politics of voluntary and in voluntary identities: are Muslims in Britain an ethnic, racial or religious minority? Patterns of Prejudice, 42(1), 61-81. doi:10.1080/00313220701805901

Meer, N. (2013). Racialization and religion: race, culture and difference in the study of antisemitism and Islamophobia. Ethnic and Racial Studies, 36(3), 500-515. doi:10.1080/01419870.2013.734382

Moosavi, L. (2002). British Muslim converts performing 'authentic Muslimness.' Performing Islam, 1(1), 103-128. doi:10.1386/pi.1.1.103_1

Moosavi, L. (2015). The racialization of Muslim converts in Britain and their experiences of 
Islamophobia. Critical Sociology, 41(1), 41-56. doi:10.1177/0896920513504601

Office for National Statistics. (2011). Census 2011. Retrieved from

https://www.ons.gov.uk/peoplepopulationandcommunity/culturalidentity/religion/article s/fullstorywhatdoesthecensustellusaboutreligionin2011/2013-05-16\#religion-byethnicity

Özyürek. (2015). Being German Becoming Muslim: Race, Religion, and Conversion in th New Europe. Princeton, NJ: Princeton University Press.

Pehrson, S., \& Green, E. (2010). Who We Are and Who Can Join Us: National Identity Content and Entry Criteria for New Immigrants. Journal of Social Issues, 66(4), 695716. doi:10.1111/j.1540-4560.2010.01671.x

Petsko, C. D., \& Bodenhausen, G. V. (2019). Racial stereotyping of gay men: Can a minority sexual orientation erase race? Journal of Experimental Social Psychology, 83, 37-54. doi:10.1016/j.jesp.2019.03.002

Phillips, D. (2006). Parallel lives? Challenging discourses of British Muslim self-segregation. Environment and Planning D: Society and Space, 24, 25-40. doi:10.1068/d60j

Phoenix, A. (1994). Practising feminist research: the intersection of gender and race in the research process. In M. Maynard \& J. Purvis (Eds.), Researching Women's Lives from a Feminist perspective. London: Taylor \& Francis.

Reicher, S. (2004). The context of social identity: Domination, resistance, and change. Political Psychology, 25(6), 921-945. doi:10.1111/j.1467-9221.2004.00403.x

Reicher, S. (2016). Oh dear, what can the matter be? A commentary on Pratto's “On power and empowerment.” British Journal of Social Psychology, 55(1), 21-26. doi:10.1111/bjso. 12136

Reicher, S., Spears, R., \& Haslam, S. A. (2010). The Social Identity Approach in Social Psychology. In M. S. Wetherell \& C. T. Mohanty (Eds.), Sage Identities Handbook (pp. 
45-62). London: Sage.

Schlossberg, L. (2001). Introduction: Rites of passing. In M. C. Sanchez \& L. Schlossberg (Eds.), Passing: Identity and Interpretation in Sexuality, Race and Religion (pp. 1-12). New York: New York University Press.

Suleiman, Y. (2013). Narratives of Conversion to Islam in Britain: Female Perspectives.

Retrieved from http://www.cis.cam.ac.uk/wp-conte nt/uploa ds/2016/01/narra tives_of_conve rsion_report.pdf

Tajfel, H., \& Turner, J. C. (1979). An integrative theory of intergroup conflict. In W. G.

Austin \& S. Worchel (Eds.), The Social Psychology of Integroup Relations (pp. 33-47). Monterey, CA: Brooks/Cole.

Tajfel, H., \& Turner, J. C. (1986). The social identity theory of inter-group behavior. In S. Worchel \& L. W. Austin (Eds.), Psychology of Intergroup Relations. (pp. 7-24). Chicago, IL: Nelson-Hall.

Taylor, C. (1994). The Politics of Recognition. In A. Gutmann (Ed.), Multiculturalism: Examining the Politics of Recognition (pp. 25-73). Princeton: Princeton University Press. doi:10.1037/a0020654

Turner, J. C. (2005). Explaining the nature of power: A three-process theory. European Journal of Social Psychology, 35(1), 1-22. doi:10.1002/ejsp.244

Turner, J. C., Hogg, M., Oakes, P., Reicher, S., \& Wetherell, M. (1987). Rediscovering the Social Group: A Self-Categorization Theory. Oxford: Blackwell.

Vaos, D. (2013, June). Census 2011: Muslims in Britain. British Religion in Numbers. Retrieved from http://www.brin.ac.uk/2013/census-2011-muslims-in-britain/ Vorauer, J. D., Hunter, A. J., Main, K. J., \& Roy, S. A. (2000). Meta-stereotype activation: Evidence from indirect measures for specific evaluative concerns experienced by members of dominant groups in intergroup interaction. Journal of Personality and 
Social Psychology, 78(4), 690-707. doi:10.1037//0022-3514.78.4.690

Wagner, W., Sen, R., Permanadeli, R., \& Howarth, C. S. (2012). The veil and Muslim women's identity: cultural pressures and resistance to stereotyping. Culture \& Psychology, 18(4), 521-541. doi:10.1177/1354067X12456713

Wang, J., Minervino, C., \& Cheryan, S. (2013). Generational differences in vulnerability to identity denial: The role of group identification. Group Processes and Intergroup Relations, 16(5), 600-617. doi:10.1177/1368430212461963

Wykes, E. J. (2013). The racialisation of names: names and the persistence of racism in the $U K$. Notthingham University.

Zlatanović, S. (2017). Approaching preferred identity: 'Serbian Gypsies’ in post-war Kosovo. Romani Studies, 27(2), 147-172. doi:10.3828/rs.2017.9 